JPCH Short Case: Dysmorphology (title page)

\title{
SHORT CASE: AN APPROACH TO THE CHILD WITH DYSMORPHIC FEATURES
}

Dr Jonathan Kaufman 1,3, Dr Susan M. White 2,3

1 Royal Children's Hospital, Melbourne, Victoria

2 Victorian Clinical Genetics Services, Murdoch Childrens Research Institute, Melbourne, Victoria

3.Department of Paediatrics, University of Melbourne, Victoria

SHORT CASE ARTICLE

CORRESPONDING AUTHOR

Dr Jonathan Kaufman

15 Allan St, Brunswick 3056

jonathan.kaufman@rch.org.au

CONFLICTS OF INTEREST

There are no conflicts of interest to declare.

\section{RELATIONSHIPS}

Dr Kaufman is the course convenor of Genetics For Trainees, an independent educational course for paediatric and physician trainees. Dr White is a lecturer at the Genetics For Trainees course.

Dr White is a lecturer for hospital based genetics teaching for paediatric basic trainees. Dr Kaufman has previously arranged hospital based exam tutorials for paediatric basic trainees in his former role as Deputy Chief Resident Medical Officer, 2014.

This is the author manuscript accepted for publication and has undergone full peer review but has not been through the copyediting, typesetting, pagination and proofreading process, which may lead to differences between this version and the Version of Record. Please cite this article as doi: 10.1111/jpc.13316

This article is protected by copyright. All rights reserved. 


\section{SHORT CASE: AN APPROACH TO THE CHILD WITH DYSMORPHIC FEATURES}

Like all short cases, the aim of the dysmorphology examination is to reach a focused list of differential diagnoses, which requires a systematic and structured examination. Have a general approach in mind, but tailor what is appropriate for the patient in front of you. Many of these principles will also apply in the long case physical examination, and in clinical practice. Comment on findings either as you go or at the end, then summarise your main findings before presenting a concise and considered differential diagnosis.

\section{INTRODUCTION TO THE DYSMORPHOLOGY SHORT CASE}

Show the child, parent and examiner that you are a kind, sensitive and considerate doctor. In any description of a child's appearance, use appropriate, neutral language. Words or phrases that could be used include 'distinctive appearance', 'different in appearance to parents', 'feature' or 'trait'. Avoid jargon or judgemental terms like 'dysmorphic', 'deformed' or 'abnormal'.

Be systematic and divide the examination into sections: start with a general inspection, then move from hands to head to face to torso to legs. Know what you are looking for and how to describe it. If in doubt, fall back on the '3S approach': Size, Shape, and Symmetry. Be flexible: depending on how the child is feeling you may need adapt your plan and stand back, change track, and just comment on what you observe.

\section{GENERAL OBSERVATIONS}

Start with your general observations, taking time to observe the child's appearance. Many trainees use a pneumonic such as 'IHUGVIDEP' to ensure they do not miss any key findings.

INTRODUCE: introduce yourself to the patient/family

HANDS: wash your hands before examining if you have not already done so UNWELL/WELL: does the child seem sick or well? 
GROWTH: measure and plot the weight, height and head circumference, and note the child's body habitus and proportions

VITALS: ask at the start for vital signs only if it seems indicated, better to check them yourself later in context

IATROGENIC: look for a feeding tube, mobility aids, toys that may give a clue regarding level of cognition, or other devices

DYSMORPHISM: what are your first impressions of the child's appearance; does he/she resemble their parents?

EXPOSE: if the child is co-operative and when appropriate, remove their shirt to look for scars, lines and skin lesions

PAIN: is the patient comfortable to be examined, and where is best to examine them: on the bed, chair, or parent's lap?

\section{HANDS \& UPPER LIMBS}

Next move to the hands. Describe the hand size, shape and symmetry. Look at the nails, finger length and shape, and palmar creases. Look at the arms, and the segment proportions, commenting on any asymmetry or joint hypermobility.

\section{HEAD}

Look at the child's head, and its size, shape, fontanelles, sutures and hair (quality, quantity). Focus on the face and its shape, symmetry, coarseness, and divide the face into thirds.

For the upper third, assess the position of the hairline and the shape of the forehead. The eyes are an important part of the examination. Start externally and work inwards noting the eyelids, palpebral fissures (length, slant), spacing, sclera, iris and pupils. Then move to the midface. Comment on the nose and its size, shape, nasal bridge, tip, nostrils and philtrum. The ears are also important and note their size, shape, position, rotation, any skin tags or creases. For the lower third of the face, look at the jaw, lips, philtrum, gums, teeth, palate, tongue, uvula, and for the presence of any midline defects. If you find one midline defect, remember to look for others. 


\section{TORSO \& SKIN}

Look specifically at the skin and any scars, neurocutaneous stigmata, or pigmentation. Look for the presence of webbing or skin folds of the neck.

Look from in front and behind at the back and chest, specifically the spine, sternum and nipples. Listen to the heart sounds as cardiac anomalies are a feature of many syndromes with dysmorphic features. Examine the abdomen for scars, hernia or the presence of organomegaly.

\section{LOWER LIMBS \& FEET}

Now move down to look at the legs and their segment proportions, comment as for the arms on any asymmetry or hypermobility. Look at the feet carefully and the nails, toes, webbing, and the foot size and shape (flat, curved, asymmetrical). Comment on footwear and mobility aids, and gait if the child is mobile.

\section{GENITALIA (consider if appropriate)}

It is often not appropriate to examine the child's genitalia in an exam scenario. Consider commenting instead on what you might look for on examination, and tell the examiner that you will not do this in the exam today. For the genitalia observe the phallus, scrotum and testes (size, development, descent) in boys, the labia in girls, and pubertal development in both. Note the position of the anus.

\section{OTHER}

Consider a targeted examination of other specific areas looking for relevant positive and negative findings based on what you have found so far. This might include checking vision and hearing, or fundoscopy, in some cases.

Think about the child's interaction and co-operation during the examination, and does this give you any clues about their development, cognition and neurology. What has their conversation and play been like? Were any characteristic behaviours, such as hand-flapping, observed? 
If the parents or siblings are present in the room, look for clues about potential inheritance patterns, or possible non-syndromic familial features.

\section{SUMMING UP}

Hopefully by now you can summarise your salient findings. Are there any conditions that could tie your findings together, or provide a differential diagnosis? What differentiating features add weight to your differentials? Mention also any relevant negative findings that assist you prioritising your list of differentials. For example in the child with short stature where you have also noted a webbed neck, consider Turner syndrome in a girl or Noonan syndrome in a boy or girl; for a child with short stature with a thumb/radial anomaly, consider Fanconi Anaemia; for a child with short stature and elfin facies consider Williams syndrome.

Complete your examination in around 10 minutes to allow time for presentation of your findings and discussion. Consider what genetic and other tests you might do to assist in finding a unifying diagnosis. If in doubt, go for microarray as the aneuploidies and microdeletion/duplication syndromes will be detected by this method.

Don't panic: finding and describing features accurately is more important than being certain of the exact diagnosis. The diagnosis may be obscure, or even unknown. Be open, but avoid making judgements especially in front of the child and parents. As always, be mindful to use sensitive language to describe your findings, even when dashing through the dysmorphology short case.

This article is protected by copyright. All rights reserved. 
Table 1: Key features on examination and syndromes to consider

\begin{tabular}{|l|l|}
\hline KEY FEATURE & SYNDROMES TO CONSIDER \\
\hline Short stature & Turner, Noonan, Russell Silver, Williams, skeletal dysplasias \\
\hline Tall stature & Marfan, Homocystinuria, Klinefelter, Sotos \\
\hline Obesity & Prader Willi, Bardet Biedl \\
\hline Pubertal delay & Turner, Klinefelter \\
\hline Aortic stenosis & Williams \\
\hline Pulmonary stenosis & Noonan, Williams, Alagille \\
\hline Conotruncal/AVSD & 22q11 deletion, trisomy 21 \\
\hline Aortic dilatation & Marfan, Ehlers Danlos \\
\hline Radial ray anomalies & Fanconi Anaemia, VACTERL, TAR, Blackfan Diamond \\
\hline Deafness & Goldenhar, CHARGE, Waardenburg, Treacher Collins, Alport, NF-2 \\
\hline Cleft lip/palate & 22q11 deletion (cleft palate), Stickler \\
\hline Café au lait macules & NF-1, Fanconi Anaemia, McCune-Albright \\
\hline
\end{tabular}




\section{University Library}

\section{- M M I E E R VA A gateway to Melbourne's research publications}

Minerva Access is the Institutional Repository of The University of Melbourne

Author/s:

Kaufman, J;White, SM

Title:

An approach to the child with dysmorphic features

Date:

2017-03-01

Citation:

Kaufman, J. \& White, S. M. (2017). An approach to the child with dysmorphic features. JOURNAL OF PAEDIATRICS AND CHILD HEALTH, 53 (3), pp.221-222. https:// doi.org/10.1111/jpc.13316.

Persistent Link:

http://hdl.handle.net/11343/292581 